\title{
OXIDATION MECHANISMS IN RELATION TO HIGH TEMPERATURE CRACK PROPAGATION PROPERTIES OF ALLOY 718 IN H2/H2O/INERT GAS ENVIRONMENT
}

\author{
P.F. Browning, M.F. Henry \\ GE Corporate R\&D,1 Research Circle, Niskayuna, NY 12309
}

K. Rajan

Rensselaer Polytechnic Institute, Materials Engrg. Dept., $1108^{\text {th }}$ Street, Troy, NY 12180

\begin{abstract}
High temperature crack propagation testing was performed under different oxygen partial pressures, ranging from $10^{-37} \mathrm{MPa}$ to $10^{-3} \mathrm{MPa}$, on specimens taken from an Alloy 718 forging. Oxygen partial pressure was varied by manipulating the hydrogen and water vapor contents of the test atmosphere while maintaining a constant total pressure of 15.7 psia. In contrast to previous results obtained in partial vacuum by other authors, crack growth rate was not a straightforward function of oxygen partial pressure. However, in agreement with the previous work, slow crack growth rates were associated with the formation of a $\mathrm{Cr}$-rich crack tip oxide scale while fast crack growth rates were associated with the formation of a $\mathrm{Ni}$ - and Fe-rich crack tip oxide scale. These conclusions are drawn through analytical electron microscopy of thin foils containing the crack tip. These results are used to discuss thermodynamic and kinetic aspects of environmental embrittlement of Alloy 718.
\end{abstract}

\section{Introduction}

Speidel [1] has proposed that the rate of fatigue crack propagation, da/dN, for materials tested under cycle dependent conditions is a function of only the elastic modulus of the material and the applied stress intensity range. However, for many materials, Speidel's predictions can grossly underestimate the crack propagation rate when testing is performed under conditions to which many of the components of modern gas turbines are exposed, i.e. long periods at maximum load, elevated temperatures and aggressive environments. The increase in crack propagation rate that is observed under these conditions occurs as a result of a phenomenon that has been termed time dependent crack propagation [3], or creep-fatigue. For Ni-base superalloys such as Alloy 718 , lab air is a sufficiently aggressive environment and time dependent crack propagation in lab air has been reported for Alloy 718 at temperatures as low as $425^{\circ} \mathrm{C}$ [4]. Time dependent crack propagation is a thermally activated process[5-9], and with the ever-increasing temperatures and stresses to which designers subject critical gas turbine components, the time dependent fatigue properties of Ni-base superalloys become increasingly important in determining component life.

Oxygen partial pressure effects on crack growth

There is no consensus in the literature as to the mechanism responsible for time dependent crack propagation in laboratory air environments. However, most of the many mechanisms

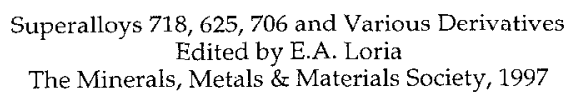




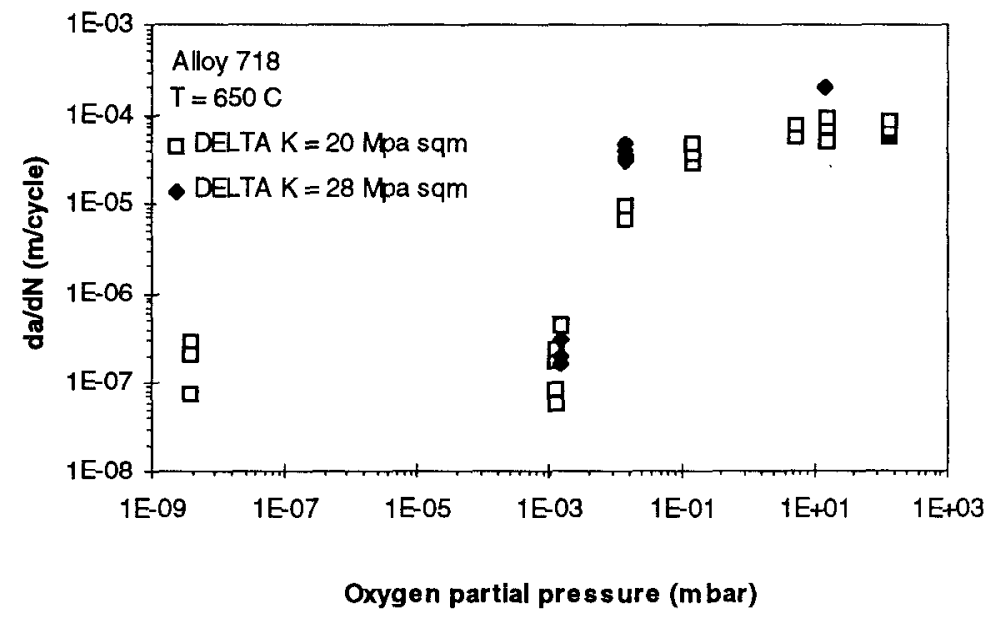

Figure 1. Crack propagation rate versus oxygen partial pressure for Alloy 718 tested in partial vacuum at $650{ }^{\circ} \mathrm{C}$ and $\Delta K$ 's of 20 and $28 \mathrm{MPa} \mathrm{m}^{1 / 2}$ from reference [17]. A trapezoidal loading waveform, with $300 \mathrm{sec}$. hold and $10 \mathrm{sec}$. ramps was used.

which have been proposed assume that oxygen is the damaging atmospheric species [10-16]. This assumption has been supported with elevated temperature crack propagation testing in vacuum[17-19], as well as inert gas environments[16,20,21], where it has been shown that the time dependent crack propagation rate of many materials is substantially lower than in laboratory air.

To add further support to this assumption, Andrieu et. al.[17] have recently reported measurements of the time dependent crack propagation rate of the Ni-base superalloy Alloy 718 in controlled partial vacuum environments. Their results, reproduced in Figure 1, show that at oxygen partial pressures in excess of $10^{-4} \mathrm{MPa}(1 \mathrm{mbar})$, the crack propagation rate was relatively unaffected by oxygen partial pressure. At oxygen partial pressures below $10^{-7}$ $\mathrm{MPa}\left(10^{-3} \mathrm{mbar}\right)$, the crack propagation rate was again independent of oxygen partial pressure, but was approximately two orders of magnitude slower than in the high oxygen partial pressure case. For the intermediate case, i.e. oxygen partial pressures between $10^{-7}$ and $10^{4}$ $\mathrm{MPa}$, the crack propagation rate was found to be highly dependent on oxygen partial pressure.

Fracture surfacc oxide phase formation

In the previously referenced work by Andrieu et. al., auger electron spectroscopy (AES) sputter depth profiling was used to characterize the fracture surface oxide scales that formed at various oxygen partial pressures. It was shown that, at oxygen partial pressures in excess of $10^{-3} \mathrm{MPa}$, the formation of a $\mathrm{Ni}$ - and Fe-rich oxide was favored, while at oxygen partial pressures below $10^{-7} \mathrm{MPa}$, the favored oxide phase was $\mathrm{Cr}$-rich. This transition in oxide phase stability was shown to occur for oxide scale which formed on the fracture surface as well as on an exposed surface of the specimen. From these results, Andrieu concluded that oxide phase stability played an important role in controlling the rate of time dependent crack propagation of Alloy 718 in laboratory air, with a transition to a more passive oxide film at lower oxygen partial pressures leading to a reduced crack growth rate. In analogous work in aqueous environments, Dawson and Pelloux [22] have demonstrated that the formation of a passive oxide film at the crack tip can substantially decrease time dependent crack propagation rates in aqueous environments. 
In the work that will be presented here, the approach of Andrieu et. al. will be modified such that control of oxygen partial pressure is achieved with a reduction-oxidation reaction between hydrogen and water vapor rather than with partial vacuum.

\section{Procedure}

Compact tension specimens, having a fracture mechanics width of $40.6 \mathrm{~mm}$ (1.6 inch) and a thickness of $6.35 \mathrm{~mm}(0.25 \mathrm{inch})$ were used for all testing. All other specimen dimensions conform to ASTM standard E647. Test specimens were taken from an Alloy 718 pancake forging. Specimen orientation was L-R (loading axis along longitudinal forging direction, crack propagation direction along radial forging direction). Specimens were precracked 2.54 $\mathrm{mm}(0.1 \mathrm{inch})$ from the starter notch at room temperature, stress intensity range $\Delta \mathrm{K}=22 \mathrm{MPa}$ $\mathrm{m}^{1 / 2}$, load ratio of $\mathrm{R}=0.1$ and cyclic frequency of $20 \mathrm{~Hz}$. Crack Propagation testing was performed on a servohydraulic test frame using reversing d.c. electrical potential drop (RDCEPD) crack length monitoring to provide a constant stress intensity through closed-loop load control. See Catlin et. al. [23] for a detailed description of this technique. The test specimen was enclosed in a 4 liter stainless steel autoclave manufactured by Autoclave Engineers Inc.

For all but one test specimen, oxygen partial pressure in the test atmosphere was controlled using a flowing gas mixture containing various partial pressures of hydrogen, water vapor and argon. One additional test was performed using a mixture of oxygen, argon and water vapor. The moisture content of the test atmosphere was controlled using the delivery system shown schematically in Figure 2. To produce moist gas mixtures, a dry gas mixture was supplied from a single gas cylinder containing a vendor certified mixture of two gasses (either hydrogen and argon, or oxygen and argon). This gas mixture was transported through stainless steel tubing to an MKS Mass-Flo ${ }^{\circledR}$ Controller. A mass flow rate of 500 SCCM was maintained. The gas mixture was then saturated with water vapor by bubbling it through $2.5 \mathrm{~L}$ of high purity water maintained at a temperature of $80^{\circ} \mathrm{C}$ and contained within a $5 \mathrm{~L}$ glass ball, the upper half of which was maintained at a temperature of $90^{\circ} \mathrm{C}$ to prevent condensation. The water-saturated gas mixture was then transported through heated $1 / 4$ " stainless steel tubing to a second glass chamber. This second glass chamber was filled with $4 \mathrm{~mm}$ diameter glass balls and was submerged in a stirred constant temperature distilled water bath. The constant temperature water bath was maintained at the temperature of the desired gas dewpoint. Excess moisture in the gas mixture condensed in the second chamber and was removed through a sump which was connected to a siphon. The siphon reservoir was elevated such that the water level in the siphon reservoir was 28 inches above the water level in the second glass chamber so that a positive pressure of 1 psig could be maintained in the delivery system by manipulation of a valved orifice on the outlet of the test autoclave. Temperature control in the constant temperature water bath was to within $\pm 0.1^{\circ} \mathrm{C}$. The effluent mixture from this chamber then passed through heated 1/4" stainless steel tubing to the test autoclave. All heated tubing in the atmosphere delivery system was maintained at a temperature of between 120 and $160^{\circ} \mathrm{C}$. The temperature of the heated tubing was monitored in 10 locations using spot-welded type $\mathrm{K}$ thermocouples.

Dry gas mixtures were delivered directly from the mass flow controller to the test autoclave through room temperature 1/4" stainless steel tubing (see Figure 2). 


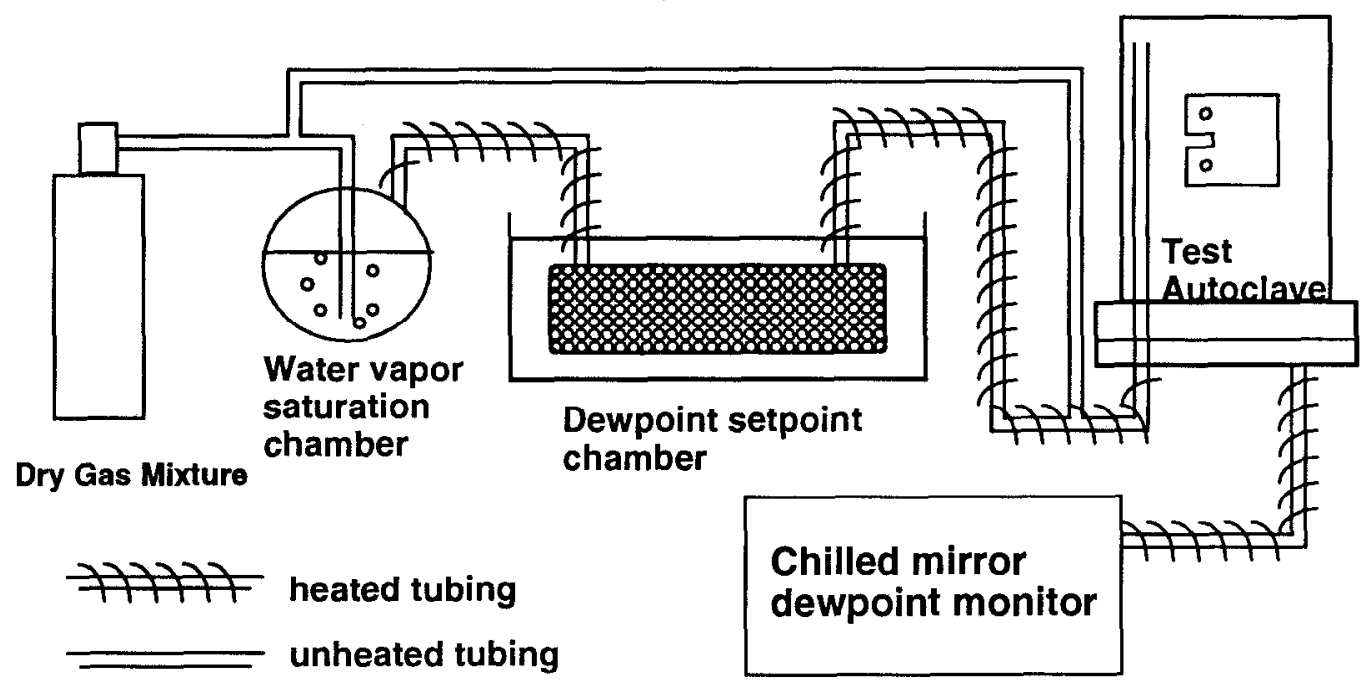

Figure 2: Schematic diagram of RedOx atmosphere testing apparatus. A dry gas mixture flows from a gas cylinder into chamber $A$, where it is saturated with water vapor. The moist gas mixture then flows into chamber $B$, which is maintained at a lower temperature by immersion in a constant temperature circulating bath and at constant positive pressure of 1 psig by elevated siphon system. The bath temperature determines the dewpoint of the gas mixture exiting chamber $B$. This mixture flows through heated lines into the test autoclave and then into a chilled mirror dewpoint monitor.

Incoming gas mixtures were introduced into the top of the test autoclave, while effluent gasses were removed through the base of the autoclave through heated 1/4" stainless steel tubing. The effluent gas mixture was passed through one of two General Eastern dewpoint sensors. General Eastern sensor model 1311XR, which was capable of measuring dewpoints of between -80 and $10^{\circ} \mathrm{C}$, was used to measure the dewpoint of dry gas mixtures, while General Eastern sensor model SIM-12H, which was capable of measuring dewpoints of between -25 and $80^{\circ} \mathrm{C}$, was used to measure the dewpoint of moist gas mixtures. The measured dewpoint of moist gas mixtures was found to be within $\pm 1^{\circ} \mathrm{C}$ of the constant temperature water bath temperature, and all dewpoint measurements were within $\pm 0.5^{\circ} \mathrm{C}$ of the reported average value. Notice that in this testing, although oxygen partial pressure was manipulated over many orders of magnitude, the total pressure in the test autoclave was fixed for all testing at $1 \mathrm{psig}$.

Transmission electron microscopy (TEM) was performed using a JEOL 2010 EM operated at $200 \mathrm{kV}$. Compact tensions specimens that had been tested in a given environment at $593^{\circ} \mathrm{C}$ $\left(1100^{\circ} \mathrm{F}\right)$ were sectioned using a diamond saw and thin foils containing the crack tip were prepared by ion-milling of a dimpled foil. Phase identification was performed using X-ray compositional spectra and analysis of selected area diffraction patterns. 


\section{$\underline{\text { Results }}$}

Three studies of the effects of oxygen partial pressure and water vapor partial pressure on the time dependent crack propagation rate of Alloy 718 were performed.

Crack growth rate as a function of cyclic period in various environments

In the first study, crack propagation rates were measured at a constant stress intensity range of $\Delta \mathrm{K}=27.5 \mathrm{MPa} \mathrm{m} \mathrm{m}^{*}(25 \mathrm{ksi}$ in $)$, load ratio of $\mathrm{R}=0.1$ and a temperature of $593^{\circ} \mathrm{C}\left(1100^{\circ} \mathrm{F}\right)$ as a function of cyclic period for a given gas mixture. For each gas mixture, these data were collected from a single specimen by periodically increasing the cyclic period during a test. The final condition was one in which the cyclic loading was stopped entirely and a constant stress intensity of $30.5 \mathrm{MPa} \mathrm{m}^{1 / 2}\left(28 \mathrm{ksi} \mathrm{in}^{1 / 2}\right)$ was maintained. Gas mixtures of dry hydrogen, moist argon and laboratory air were investigated. Figure 3 shows a plot of these data in which crack extension per unit time, $\mathrm{da} / \mathrm{dt}$, is plotted as a function of cyclic period.

Sustained load crack growth rate as a function of oxygen partial pressure

In the second study, crack propagation rate was measured as a function of oxygen partial pressure at a constant sustained stress intensity of $\mathrm{K}=30.5 \mathrm{MPa} \mathrm{m}^{1 / 2}$ and temperature of $593^{\circ} \mathrm{C}$. Several atmospheres were investigated using a single specimen by periodically changing the gas mixture composition during testing. Thirty five (35) orders of magnitude in oxygen partial pressure were spanned during this testing by varying the hydrogen:argon ratio and dewpoint of the gas mixture. Figure 4 shows a plot of these data in which crack propagation rate per unit time, $\mathrm{da} / \mathrm{dt}$, is plotted versus calculated equilibrium oxygen partial pressure for testing at $593^{\circ} \mathrm{C}$ and a constant stress intensity of $30.5 \mathrm{MPa} \mathrm{m}^{1 / 2}$. Figure 4 shows that at an oxygen partial pressure of approximately $10^{-27} \mathrm{MPa}$ there is an abrupt decrease of

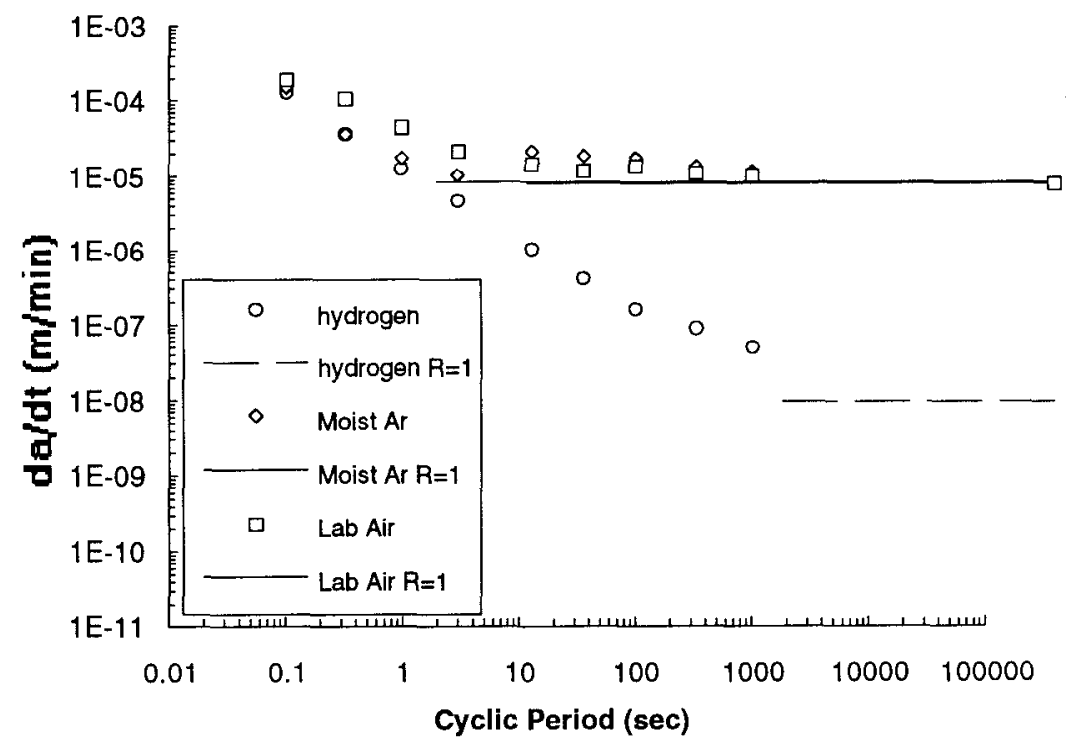

Figure 3. Crack extension per unit time plotted as a function of cyclic period a constant stress intensity range for test atmospheres of laboratory air, moist argon and dry hydrogen. Test temperature is $593^{\circ} \mathrm{C}, \Delta \mathrm{K}=27.5 \mathrm{MPa} \mathrm{m}^{1 / 2} . R=0.1$ for all data points, $R=1$ (sustained loading) for horizontal lines. The horizontal lines indicating lab air and moist argon sustained load results fall on top of one another. 
two to three orders of magnitude in the crack propagation rate. For oxygen partial pressures above and below this value, the crack propagation rate is relatively constant. However, the crack propagation rate for all moist gas mixtures exceeds that for all dry gas mixtures and thus raises the question as to whether water vapor plays a role in determining the time dependent crack propagation rate of Alloy 718 . This question is particularly pertinent because the two dry gas data points with the highest crack growth rates were generated using a gas cylinder that had an unusually high dewpoint of $-61^{\circ} \mathrm{C}$.

Sustained load crack growth at constant $\mathrm{pO}_{2}$ as a function of $\mathrm{pH}_{2} \mathrm{O}$

Because the data in Figure 4 do not allow one to determine whether oxygen partial pressure or water vapor partial pressure is controlling the time dependent crack propagation rate of Alloy 718 , a third experiment was run in which oxygen partial pressure was maintained at a constant value while the dewpoint was varied from $-57.5^{\circ} \mathrm{C}$ to $+43^{\circ} \mathrm{C}$. This was accomplished using a dry gas mixture of $0.5 \%$ oxygen in argon and adding various amounts of water vapor to the mixture. The amount of oxygen present in the dry gas mixture was orders of magnitude higher than any oxygen which would be generated from dissociation of added water vapor and the oxygen partial pressure was therefore essentially constant for all dewpoints. All testing was performed at a temperature of $593^{\circ} \mathrm{C}$ and a constant stress intensity of $30.5 \mathrm{MPa} \mathrm{m} \mathrm{m}^{1 / 2}$. These data, along with the data from Figure 4 are shown in Figure 5, where crack propagation rate, $\mathrm{da} / \mathrm{dt}$, is plotted versus water vapor partial pressure. The shape of the curve is similar to the one found in Figure 4, with high crack propagation rates at high $\mathrm{pH}_{2} \mathrm{O}$ and low crack propagation rates at low $\mathrm{pH}_{2} \mathrm{O}$. Notice that the moisture content of the $0.5 \% \mathrm{O}_{2}$ in $\mathrm{Ar}$ gas mixture did not affect the crack growth rate.

\section{Characterization of crack tip oxide scale}

TEM was used to perform oxide phase characterization from very near the crack tips of compact tension specimens in which sustained load crack propagation had occurred at a constant stress intensity of $30.5 \mathrm{MPa} \mathrm{m}{ }^{1 / 2}$ and a temperature of $593^{\circ} \mathrm{C}$. Thin foils were taken from three intact specimens. In each case, an area of the crack that was within $50 \mu \mathrm{m}$ of the crack tip was investigated.

Figure 6 shows a TEM image of the oxide scale formed near the tip of a crack grown in a $1 \%$ $\mathrm{H}_{2}$ in Ar environment having a dewpoint of $43^{\circ} \mathrm{C}$, where the calculated equilibrium oxygen partial pressure was $2 \times 10^{-24} \mathrm{MPa}$. The outermost layer in the scale was identificd as $\mathrm{NiO}$, having an FCC structure and lattice parameter of $4.18 \AA$. The X-ray spectrum from this layer, shown in Figure 7, indicates that it also contained appreciable amounts of $\mathrm{Fe}, \mathrm{Cr}, \mathrm{Nb}, \mathrm{Ti}$ and Mo. Next to this layer was a layer of austenite (FCC Ni). The X-ray spectrum from this layer is shown in Figure 8. The layer nearest the IN718 matrix was an $\mathrm{Fe}$ - and $\mathrm{Cr}$-rich oxide. It was identified as $\mathrm{FeCr}_{2} \mathrm{O}_{4}$ and had a lattice parameter of $8.38 \AA$. The X-ray spectrum from this layer is shown in Figure 9. Also shown, in Figure 10, is the X-ray spectrum and diffraction pattern from the phase marked $\mathrm{Nb}$-rich oxide. An X-ray spectrum elemental mapping study of this specimen indicated that $\mathrm{NiO}$ was the only phase that clearly formed a continuous layer. The austenite and $\mathrm{Nb}$-rich oxide were discontinuous.

Investigation of the oxide scale formed near the tip of a crack grown in a moist argon environment having a dew point of $43^{\circ} \mathrm{C}$, where the calculated equilibrium oxygen partial 


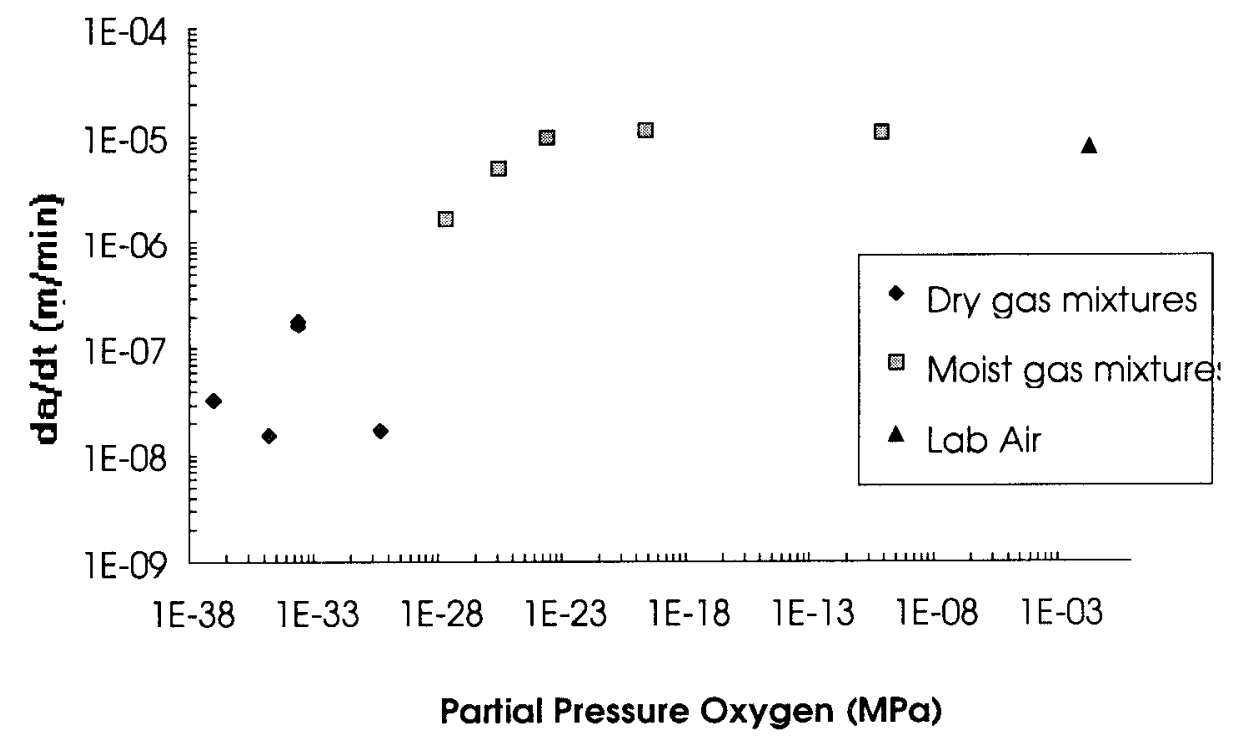

Figure 4: Sustained load crack propagation rate versus calculated equilibrium oxygen partial pressure for IN718 tested in $\mathrm{H}_{2} / \mathrm{H}_{2} \mathrm{O} / \mathrm{Ar}$ environments at $593^{\circ} \mathrm{C}$ and a constant stress intensity of $30.5 \mathrm{MPa} \mathrm{m}^{1 / 2}$. There is a decrease in crack propagation rate of two to three orders of magnitude for oxygen partial pressures below $10^{27}$ MPa.

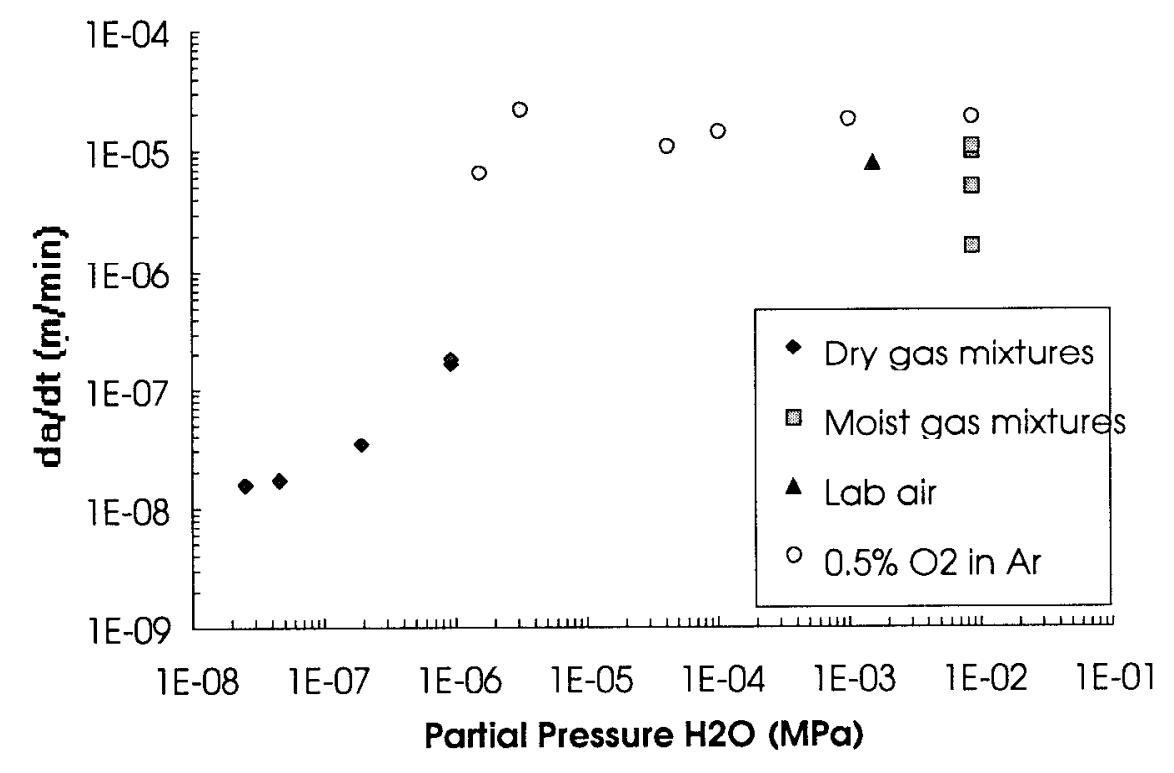

Figure 5. Sustained load crack propagation rate versus calculated equilibrium water vapor partial pressure for IN718 tested in $\mathrm{H}_{2} / \mathrm{H}_{2} \mathrm{O} / \mathrm{Ar}$ and $\mathrm{O}_{2} / \mathrm{H}_{2} \mathrm{O} / \mathrm{Ar}$ environments at $593^{\circ} \mathrm{C}$ and a constant stress intensity of $30.5 \mathrm{MPa} \mathrm{m}^{1 / 2}$. There is a decrease in crack propagation rate of two to three orders of magnitude for water vapor partial pressures below $10^{6} \mathrm{MPa}$. 


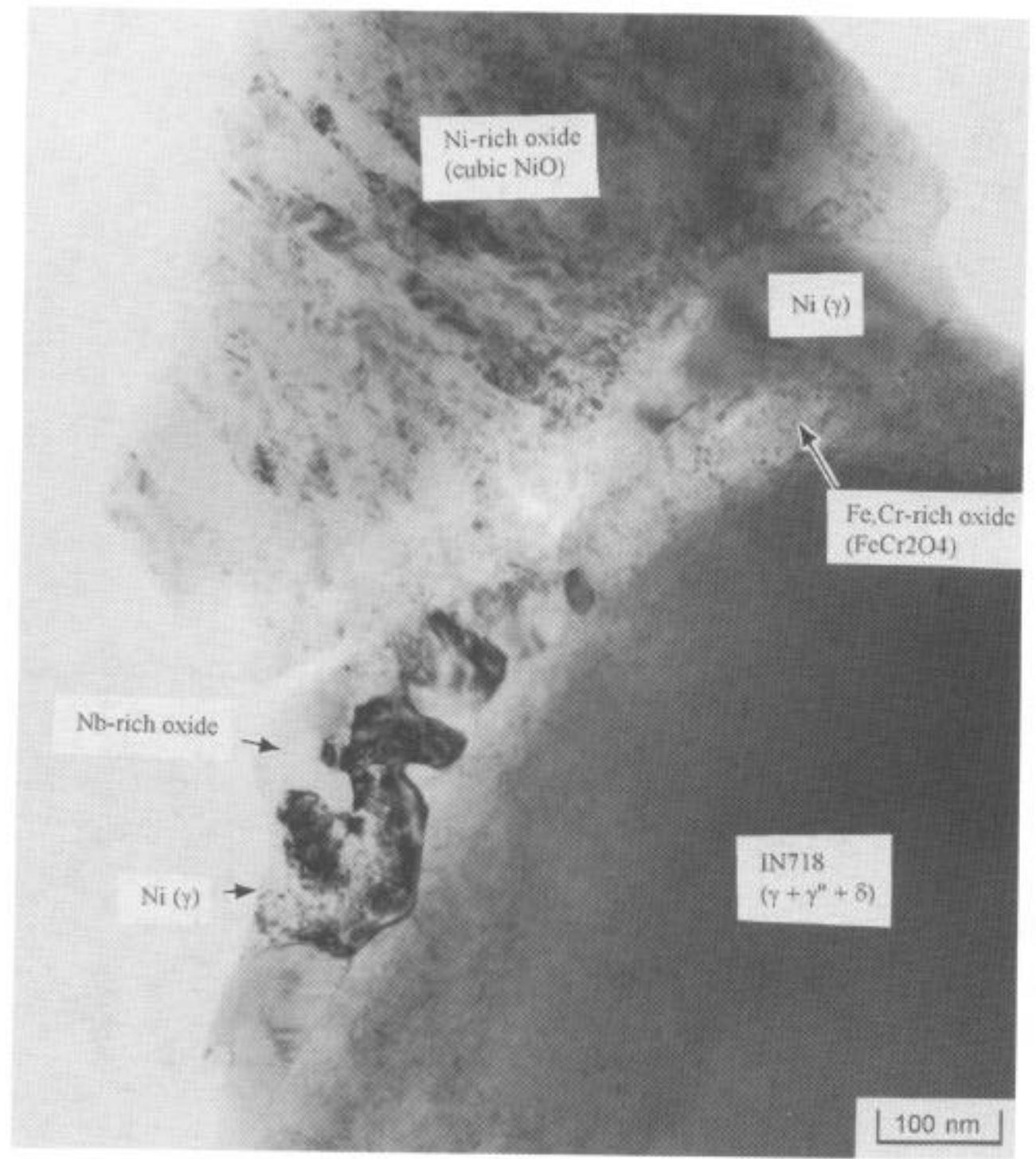

Figure 6. Transmission electron micrograph of the fracture surface oxide scale formed very near the tip of a crack grown under sustained loading in a moist gas mixture of $1 \% \mathrm{H}_{2}$ in $\mathrm{Ar}\left(43{ }^{\circ} \mathrm{C}\right.$ dewpoint). The test temperature was $593{ }^{\circ} \mathrm{C}$ and the constant stress intensity was $30.5 \mathrm{MPa} \mathrm{m}{ }^{1 / 2}$. The primary phase present in various regions of the scale is identified if a diffraction pattern was obtainable, although a given region may contain second phases. 

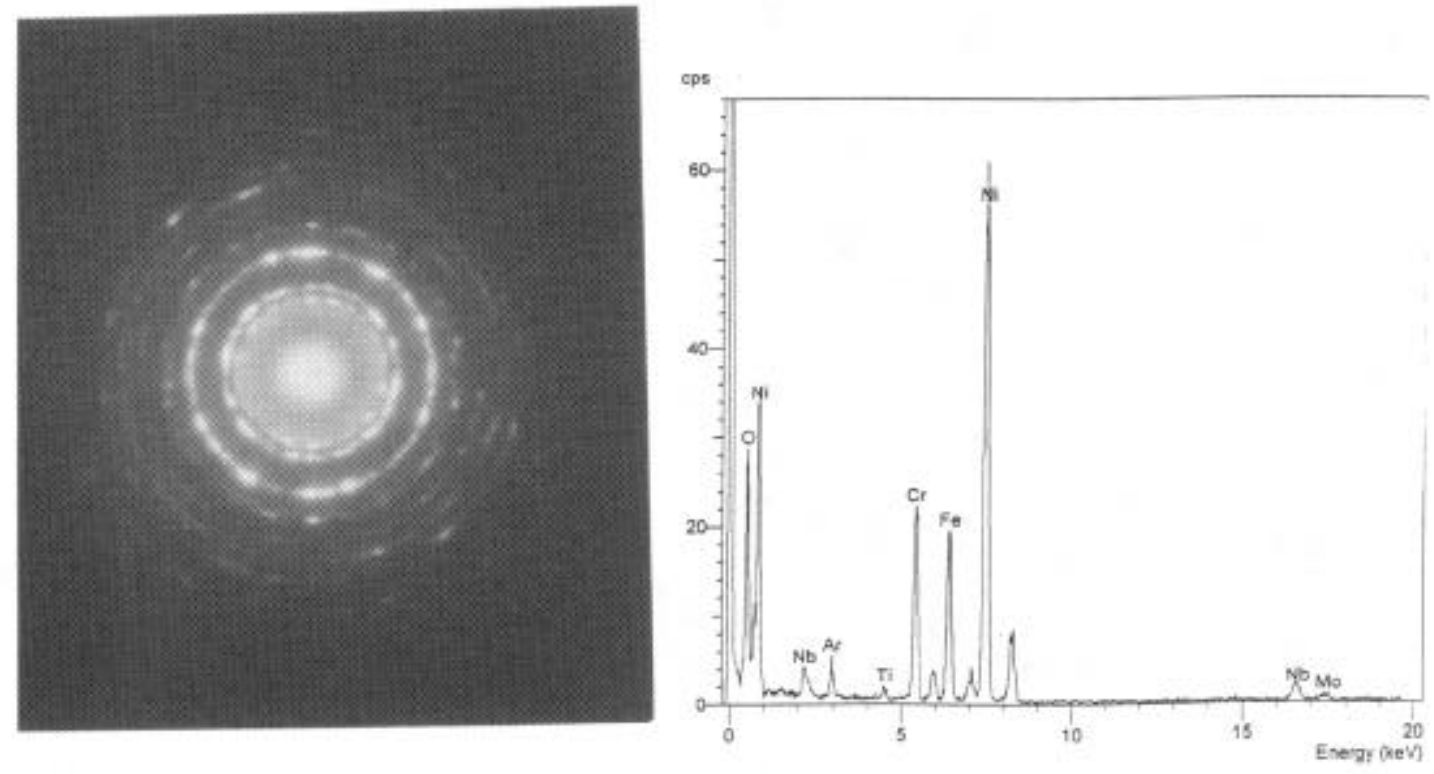

Figure 7. Elemental X-ray spectrum and selected area diffraction pattern taken from an area in the outermost layer of the scale shown in Figure 6. The diffraction pattern and elemental spectrum indicate that the primary phase in this region is $\mathrm{NiO}$, having an FCC structure and lattice parameter of $4.18 \AA$. . Appreciable quantities of $\mathrm{Cr}, \mathrm{Fe}, \mathrm{Nb}$, Mo and $\mathrm{Ti}$ may indicate the presence of second phases.
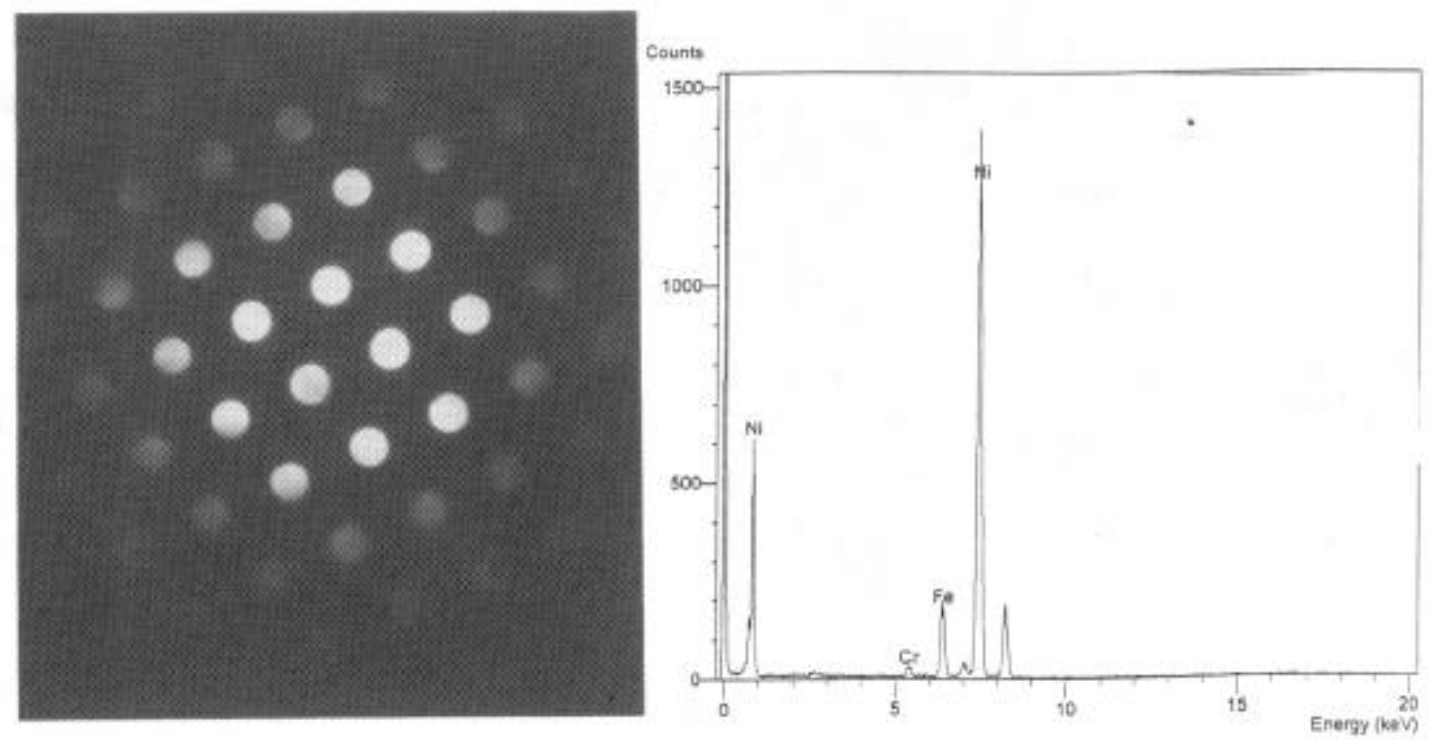

Figure 8. Elemental X-ray spectrum and selected area diffraction pattern from the area identified as " $\mathrm{Ni}(\gamma)$ " in Figure 6. The elemental spectrum and diffraction pattern identify this as austenitic nickel. 

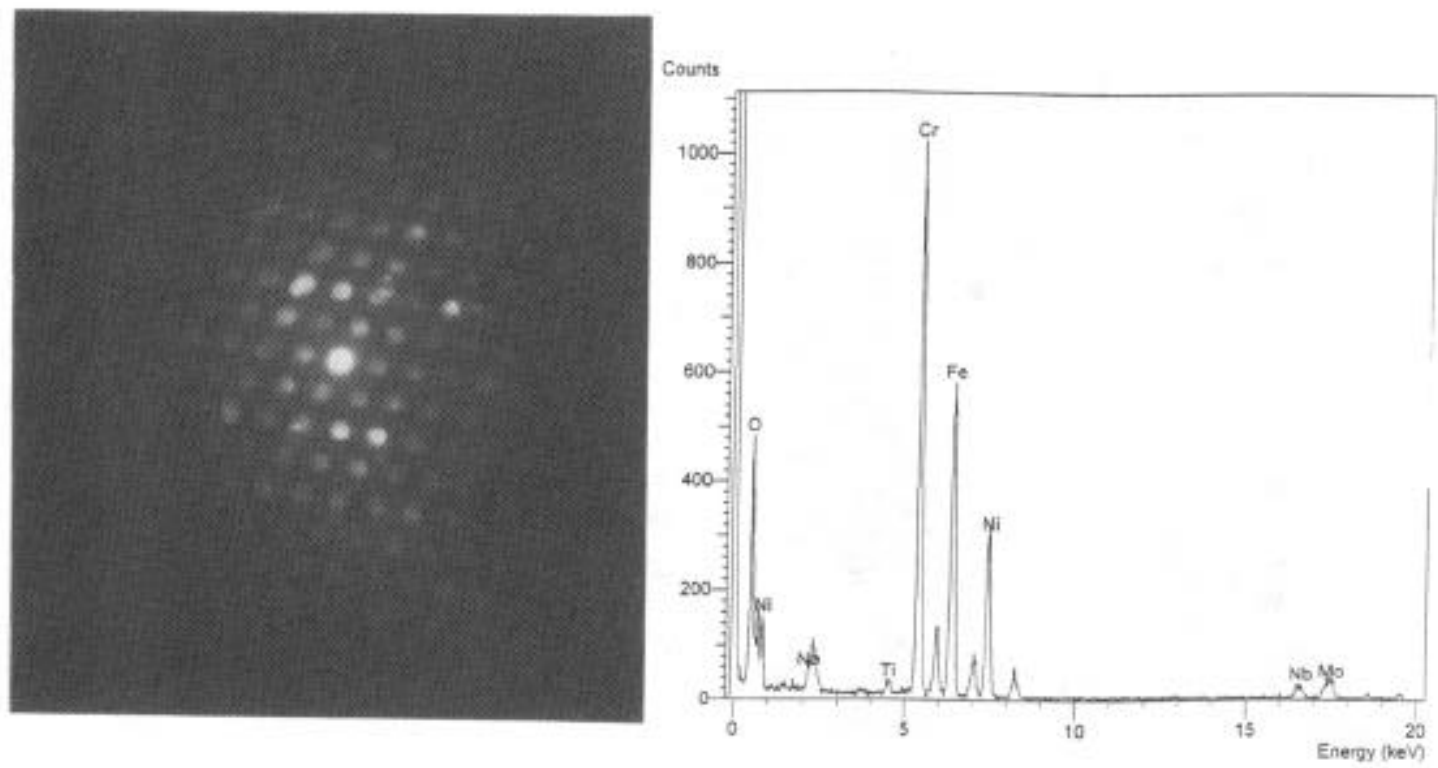

Figure 9. Elemental $X$-ray spectrum and selected area diffraction pattern from the area identified as "Fe,Cr-rich oxide" in Figure 6. The elemental spectrum and diffraction pattern identify this phase as $\mathrm{FeCr}_{2} \mathrm{O}_{4}$.
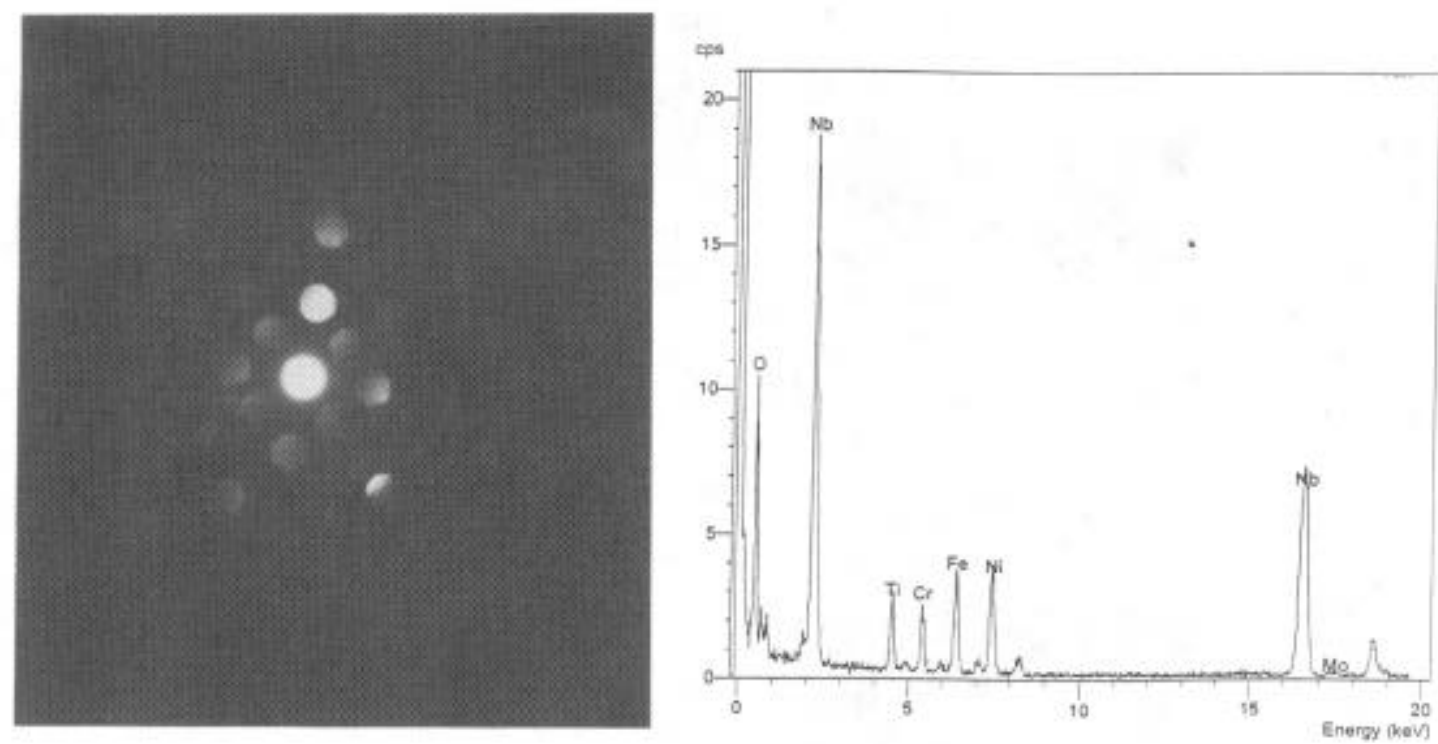

Figure 10. Elemental X-ray spectrum and selected area diffraction pattern from the area identified as "Nb-rich oxide" in Figure 6. The elemental spectrum and diffraction pattern identify this as a $\mathrm{Nb}$-rich oxide phase. 


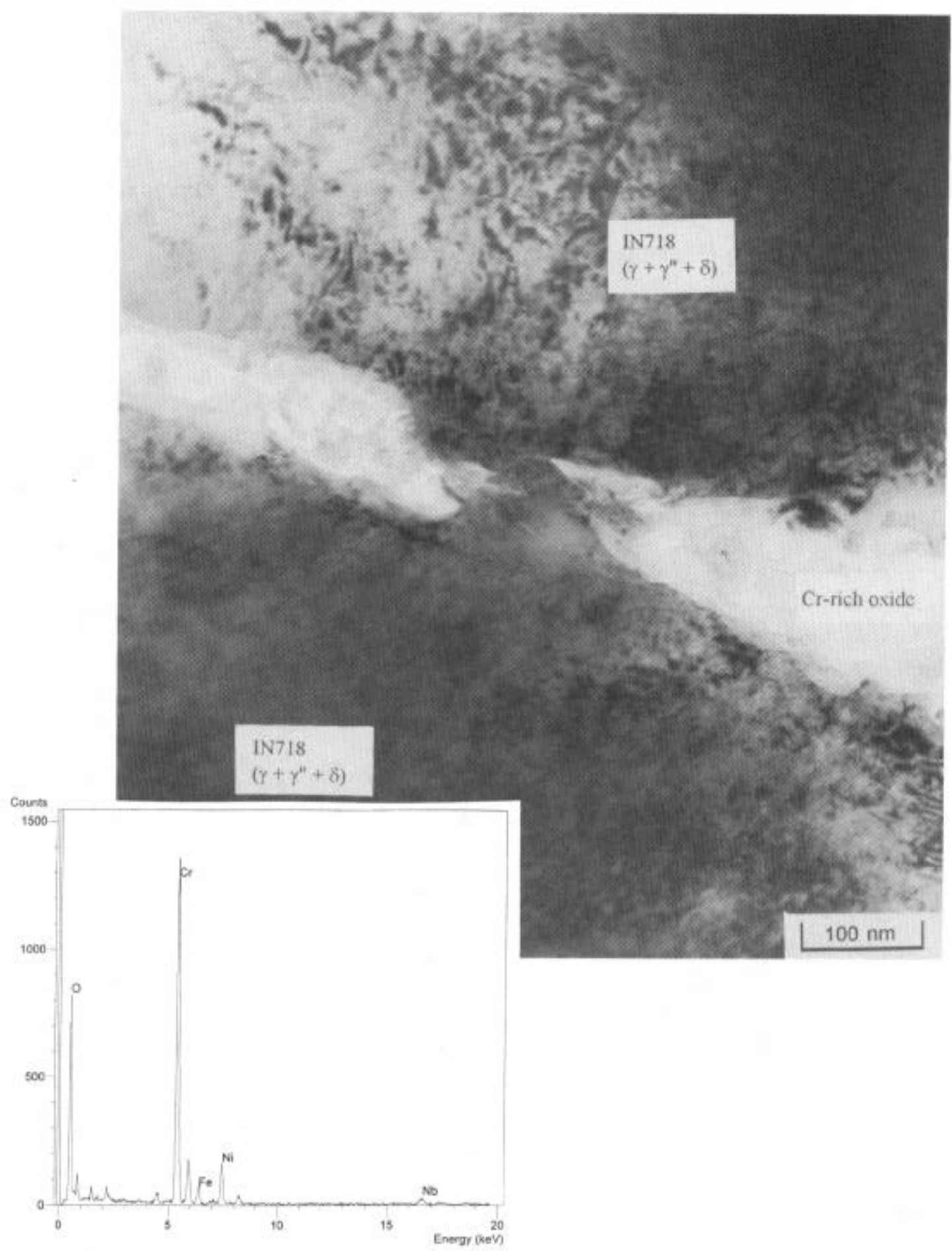

Figure 11. Transmission electron micrograph of the fracture surface oxide scale formed very near the tip of a crack grown under sustained loading in a dry hydrogen environment $\left(-72{ }^{\circ} \mathrm{C}\right.$ dewpoint). The test temperature was $593{ }^{\circ} \mathrm{C}$ and the constant stress intensity was $30.5 \mathrm{MPa} \mathrm{m}^{1 / 2}$. Only a $\mathrm{Cr}$-rich oxide phase was found in this scale. The elemental X-ray spectrum from the area identified as "Cr-rich oxide" is shown. The region was too thick to obtain a selected area diffraction pattern. The elemental spectrum indicates that this phase is a $\mathrm{Cr}$-rich oxide. 
pressure was $8 \times 10^{-11} \mathrm{MPa}$ yielded similar results - an $\mathrm{NiO}$ outer layer with austenite and an $\mathrm{Fe}$, Cr-rich spinel underneath. The Nb-rich oxide was not found in this specimen.

In contrast, Figure 11 shows the oxide scale formed near the tip of a crack grown in a dry hydrogen environment having a dewpoint of $-72^{\circ} \mathrm{C}$, where the calculated equilibrium oxygen partial pressure was $9 \times 10^{-38} \mathrm{MPa}$. The oxide scale in this specimen was distinctly different than the others. Only a Cr-rich oxide phase was present. In addition, electron diffraction of the matrix on either side of the crack indicated that this portion of the crack was transgranular. The $\mathrm{X}$-ray spectrum for the $\mathrm{Cr}$-rich oxide is also shown.

\section{Discussion}

A significant result of this work is the finding that high crack growth rates can persist in Alloy 718 at oxygen partial pressures as low as $10^{-27} \mathrm{MPa}$ when testing is performed at atmospheric pressure in a high moisture content environment. This differs by approximately 20 orders of magnitude from the value measured by Andrieu et. al. in partial vacuum. However, despite this gross difference in oxygen partial pressure effects, results of characterization of the phases formed in the crack tip oxide scale are in close agreement with those of Andrieu. Fast crack growth rates are associated with the formation of primarily $\mathrm{Ni}$ - and $\mathrm{Fe}$-rich oxides, while slow crack growth rates are associated with the formation of $\mathrm{Cr}$-rich oxides. Finally, we have the observation that crack growth rates in Alloy 718 seem to correlate better with water vapor partial pressure than with oxygen partial pressure in this set of experiments.

One way to rationalize these results is to consider that kinetic processes, rather than thermodynamic phase stability, are determining crack tip oxide phase formation. From inspection of the Ellingham diagram, this seems highly likely. The oxygen partial pressure for which Andrieu found a transition from the formation of $\mathrm{Fe}$ - and $\mathrm{Ni}$ - rich oxides to $\mathrm{Cr}$-rich oxide is many orders of magnitude too high to be explained by any thermodynamic consideration. However, the transition oxygen partial pressure of $10^{-27} \mathrm{MPa}$ measured in the present work is in general accordance with the oxygen partial pressure at which one would expect that $\mathrm{Fe}$ - and $\mathrm{Ni}$ - rich oxides would become thermodynamically unstable.

This interpretation would imply that in dry environment at oxygen partial pressures below $10^{-7}$ $\mathrm{MPa}$, the rate of $\mathrm{Fe}$ - and Ni-rich oxide formation is reduced to such an extent relative to the rate of $\mathrm{Cr}$-rich oxide formation that growth of the $\mathrm{Cr}$-rich oxide dominates. Furthermore, in moist environment, the kinetics of Fe- and Ni-rich oxide formation must be fast enough that thermodynamic considerations determine which oxide phase will form.

An alternative rationalization of these results with those of Andrieu is that the oxygen partial pressure at the crack tip may be much different from that of the bulk atmosphere. For instance, RedOx environments (such as $\mathrm{H}_{2} / \mathrm{H}_{2} \mathrm{O}$ ) are known to be highly buffered systems[24], while partial vacuum environment is not. For the case of an oxygen-containing atmosphere, a buffered system is one in which a reducing and an oxidizing atmospheric species are present in much greater abundance than is the diatomic oxygen molecule. In such a system, addition or subtraction of atmospheric $\mathrm{O}_{2}$ is compensated for by the strong driving force for thermodynamic equilibrium between the oxidizing and reducing species. If the oxygen partial pressure rises above the equilibrium value for some reason, $\mathrm{H}_{2}$ will oxidize and form $\mathrm{H}_{2} \mathrm{O}$ to reestablish equilibrium. If the oxygen partial pressure falls below the equilibrium value, $\mathrm{H}_{2} \mathrm{O}$ will be reduced to $\mathrm{H}_{2}$ and $\mathrm{O}_{2}$ to reestablish equilibrium. This property of RedOx atmospheres is taken advantage of in many industrial operations in which a low oxygen partial pressure is 
required in a chamber that is susceptible to leakage from the outside atmosphere. In an occluded area, such as a fatigue crack, the local oxygen partial pressure will be driven toward the value required for equilibrium between the gas phase and the solid phase. Since the equilibrium oxygen partial pressures at $593^{\circ} \mathrm{C}$ are extremely low for most metals (including $\mathrm{Ni}, \mathrm{Fe}$ and $\mathrm{Cr}$ ) relative to the oxygen partial pressures that can be obtained in partial vacuum, it may be expected that the oxygen partial pressure at the tip of a crack grown in partial vacuum in Alloy 718 may be significantly lower than in the bulk atmosphere. Conversely, in a buffered system such as $\mathrm{H}_{2} / \mathrm{H}_{2} \mathrm{O}$, the crack tip oxygen partial pressure may be maintained at or near the level in the bulk atmosphere. However, this explanation is in direct contrast to the observation by Andrieu that the same transition from $\mathrm{Fe}$ - and Ni-rich oxides to $\mathrm{Cr}$-rich oxide occurred on the side of his crack growth specimen.

Of course we must also consider the possibility that the explanation for the discrepancy in these results is that the water vapor content of the atmosphere, which was not reported in Andrieu's work, may play an important role in determining the time dependent crack propagation rate. The results of the work presented here may indicate that water vapor partial pressure, rather than oxygen partial pressure, plays the dominant role in determining the rate of time dependent crack propagation.

Further work will be required to determine which, if any, of these possibilities could explain the approximately 20 orders of magnitude difference between the critical oxygen partial pressures measured in RedOx and partial vacuum atmospheres. In particular, generation of crack growth rate data sets for which there is substantial overlap in oxygen partial pressure for moist and dry environments is necessary.

\section{Conclusions}

1) In agreement with Andrieu et al's studies of the effect of oxygen partial pressure in partial vacuum on time dependent crack propagation and crack tip oxide phase stability in Alloy 718, in $\mathrm{H}_{2} / \mathrm{H}_{2} \mathrm{O}$ /inert gas environments a transition from fast to slow crack growth rates is accompanied by a transition in crack tip oxide phase formation from $\mathrm{Fe}$ - and $\mathrm{Ni}$-rich oxides to Cr-rich oxides.

2) In substantial disagreement with Andrieu et al's partial vacuum results in which the oxygen partial pressure required to cause this transition was found to be approximately $10^{-7} \mathrm{MPa}$, the oxygen partial pressure required to cause the transition in $\mathrm{H}_{2} / \mathrm{H}_{2} \mathrm{O} /$ inert gas environments was found to be approximately $10^{-27} \mathrm{MPa}$. The reason for this gross disagreement is not yet understood, although effects of water vapor on oxidation kinetics and/or crack tip occlusion effects may contribute.

3) The results presented in this work do not allow one to determine whether oxygen or water vapor partial pressure plays the dominant role in determining the rate of time dependent crack propagation in Alloy 718.

4) At present, it appears that knowledge of the partial pressures of both oxygen and water vapor is necessary to predict crack propagation rate and crack tip oxide phase formation in Alloy 718. 


\section{Acknowledgements}

Financial support from GE Power Systems and the U.S. Department of Energy, Morgantown Energy Technology Center, PO Box 880, Collins Ferry Road, Morgantown, WV 26507-0880 is greatly appreciated. The content of this report does not necessarily reflect the positions or the policy of the Government, and no official endorsement should be inferred.

The technical input of Dr. Ann Ritter and Mr. Michael Larsen is gratefully acknowledged, with special thanks to Mr. Larsen for assistance in transmission electron microscopy studies.

\section{References}

1. M.O. Speidel, in High Temperature Materials in Gas Turbines ed. P.R. Sahm and M.O. Speidel (New York: Elsevier Publishing Company, 1974), 207-251.

2. M.E. Fine and R.O. Ritchie, in Fatigue and Microstructure, ed. M. Meshii (Metals Park, OH: ASM, 1979), 245-278.

3. K.M. Chang, M.F. Henry and M.G. Benz, JOM, December (1990) 29.

4. K. Sadananda and P. Shahinian, J. Engng. Mat. Tech., 100 (1978) 381.

5. K. Sadananda and P. Shahinian, Mat. Sci Engng., 43 (1980) 159.

6. K. Sadananda and P. Shahinian, Met Trans, 14A (1983) 1467.

7. K. Sadananda and P. Shahinian, J. Engng. Mat. Tech., 100 (1978) 381.

8. Y. Shen and P.G. Shewmon, Corrossion, September (1991) 712.

9. K.R. Bain and R.M. Pelloux, Met Trans, 15A (1984) 381.

10. D.A. Woodford and R.H. Bricknell, inTreatise on Materials Science and Technology, ed. C.L. Briant, (Academic Press, 1983), 157-199.

11. D. Bika and C.J. McMahon, Jr., Acta Metall. Mater. (1994), in press

12. D.A. Woodford and R.H. Bricknell, Met Trans, 12A (1981) 1467.

13. R.H. Cook and R.P. Skelton, Int. Met. Rev., 19 (1974) 199.

14. M. Gao, D.J. Dwyer and R.P. Wei, in Superalloys 718, 625 and 706 and Various Derivatives ed. E.A. Loria, (TMS, 1994) 581-592.

15. R.H. Bricknell, R.A. Mulford and D.A. Woodford, Met Trans, 13A (1982) 1223.

16. F. Gabrielli and R.M. Pelloux,Met Trans, 13A (1982) 1089.

17. E. Andrieu, G. Hochstetter, R. Molins and A. Pineau, in Superalloys 718, 625 and 706 and Various Derivatives ed. E.A. Loria, (TMS, 1994) 619-631.

18. H.D. Solomon and L.F. Coffin, in Fatigue at Elevated Temperatures, (ASTM STP 520, ASTM, Philadelphia, 1973), 112.

19. H.H. Smith, P. Shahinian and M.R. Achter, Trans. of Met. Soc. AIME, 245 (1969) 947.

20. S. Floreen and R.H. Kane, Fatigue of Engineering Materials and Structures 2 (1980) 401.

21. K.R. Bain, R.M. Pelloux, Met Trans, 13A (1982) 1083.

22. D.B. Dawson, R.M. Pelloux, Met Trans, 5A (1974) 723.

23. W.R. Catlin, D.C. Lord, T.A. Prater and L.F. Coffin, (Report 83CRD293, General Electric Corp. R\&D, 1983).

24. N. Birks and G.H. Meier, Introduction to High Temperature Oxidation of Metals (Edward Arnold Publishers Ltd., Bedford Square, London, 1983), 163.

25. H.J. Christ, L. Berchtold and H.G. Sockel, Oxidation of Metals 26, Nos. 1/2 (1986), 45-77. 